\title{
Intervensi Kelompok pada Remaja Korban Kekerasan dalam Hubungan Pacaran yang Mengalami Reaksi Stres Pascatrauma
}

\author{
Wiwit Puspitasari Dewi \\ Program Studi Psikologi, Universitas Pelita Harapan \\ wiwit.puspitasari@gmail.com
}

\begin{abstract}
Teenager dating violence has negative impacts for physical and mental health. Victims usually have low self-esteem, depression, anxiety, overwhelmed by fear and anger, somatic symptom, and posttraumatic stress disorder (PTSD). Victims with posttraumatic stress reaction are potentially experiencing PTSD so they need to get an immediate intervention. This study aims to measure the effectiveness of group intervention for helping victims of teenager dating violence with posttraumatic stress reaction using Recovery Technique Manual by Smith, Syregov, \& Yule. This study uses one group pretest-posttest design involving two victims of teenager dating violence with posttraumatic stress reaction that were acquired through purposive sampling. Effectiveness of five sessions of intervention was measured by comparing pretest-posttest scores of Children's Impact of Event Scale - 13 (CRIES-13), observations, and interviews. Results of CRIES-13 indicated decreasing symptoms of intrusion, avoidance, and arousal in both participants. The techniques helped participants to overcome negative emotions so they could feel calmer. They also felt positive changes in themselves that were recognized by friends. Intervention through group therapy made participants realize that they are not alone. As a conclusion, Recovery Technique Manual is considered to be an effective group therapy in treating posttraumatic stress reaction for victims of teenager dating violence.
\end{abstract}

Keywords: Dating violence, posttraumatic stress reaction, teenager, group intervention, Recovery Technique Manual

\begin{abstract}
Abstrak - Kekerasan dalam hubungan pacaran pada remaja berdampak buruk bagi kondisi fisik maupun kesehatan mental. Korban kekerasan biasanya mengalami penurunan self-esteem, depresi, kecemasan, diliputi rasa takut dan marah, gejala somatis, hingga posttraumatic stress disorder (PTSD). Korban yang mengalami reaksi pascatrauma berpotensi mengalami PTSD sehingga perlu diberikan penanganan segera. Penelitian ini bertujuan mengukur efektivitas intervensi kelompok pada remaja yang mengalami stress pascatrauma akibat kekerasan pada masa pacaran dengan menggunakan Recovery Technique Manual oleh Smith, Dyregov, dan Yule (1999). Desain penelitian ini menggunakan one group pretest-posttest dengan dua partisipan remaja yang diperoleh dengan teknik purposive sampling. Intervensi dilaksanakan dalam lima pertemuan dan pengukuran efektivitas intervensi dilakukan dengan membandingkan skor Children's Impact of Event Scale - 13 (CRIES-13) di awal dan akhir intervensi, melalui wawancara, dan observasi. Hasil penelitian menunjukkan penurunan gejala intrusion, avoidance, dan arousal pada skor CRIES-13 di kedua partisipan. Berdasarkan wawancara diketahui bahwa teknik yang diajarkan membantu mengatasi emosi negatif sehingga merasa lebih tenang. Partisipan juga merasakan perubahan positif pada diri mereka yang juga disadari oleh teman-teman di sekitarnya. Intervensi kelompok juga membuat partisipan menyadari bahwa mereka tidak sendirian. Kesimpulannya intervensi kelompok dengan
\end{abstract}


menggunakan Recovery Technique Modul terbukti efektif mengatasi reaksi stress pascatrauma pada remaja yang mengalami kekerasan dalam hubungan pacaran.

Kata kunci : Kekerasan dalam hubungan pacaran, reaksi stres pascatrauma, remaja, intervensi kelompok, Recovery Technique Manual

\section{PENDAHULUAN}

Menjalin hubungan pacaran merupakan hal yang sering terjadi pada periode remaja. Perasaan jatuh cinta yang umumnya dialami saat menjalin hubungan juga dapat membuat seorang remaja menjadi sangat bahagia (Rice, 1999). Namun perjalanan hubungan pacaran tidak sepenuhnya bisa berjalan dengan mulus. Akan ada konflik-konflik yang muncul di antara kedua individu di mana penyelesaiannya tidak selalu berjalan dengan baik. Tak jarang penyelesaian konflik tersebut diwarnai dengan adanya tindakan kekerasan yang bisa berbentuk emosional/verbal, fisik, dan seksual.

Kekerasan dalam hubungan pacaran (KDP) didefinisikan sebagai "Penggunaan cara kekerasan yang disengaja dan pemaksaan secara fisik yang bertujuan untuk mendapatkan dan mempertahankan kekuasaan dan kendali terhadap pasangan intim" (The University of Michigan Sexual Assault Prevention and Awareness Center dalam Murray, 2007, hal.8). Namun bentuk kekerasan tidak hanya dilakukan secara fisik, melainkan juga secara seksual, psikologis, dan segala hal yang bertujuan untuk mengendalikan perilaku seseorang (WHO, 2017). Kekerasan dalam hubungan pacaran sendiri memiliki berbagai istilah, di antaranya Intimate Partner Violence (IPV), relationship violence, atau dating violence (CDC, 2018). Namun hal esensial yang sama di antara semua istilah itu adalah semuanya dilakukan dalam konteks hubungan dekat.

Kekerasan dalam hubungan pacaran merupakan fenomena yang banyak terjadi di sekitar kita. Hampir sepertiga dari perempuan di dunia yang berada dalam sebuah hubungan pernah mengalami kekerasan secara fisik ataupun seksual oleh pasangan dekat mereka (WHO,
2017). Di Indonesia sendiri menurut data Komnas Perempuan setiap tahunnya, tiga kasus kekerasan terbesar terhadap perempuan di ranah personal salah satunya adalah kekerasan dalam pacaran (Komisi Nasional Perempuan, 2018). Data dari sumber yang berbeda juga menunjukkan banyaknya kasus kekerasan dalam hubungan pacaran di Indonesia. Kementrian Pemberdayaan Perempuan dan Anak menyatakan bahwa $42.7 \%$ perempuan yang belum menikah pernah mengalami kekerasan, dan dari 10.847 pelaku kekerasan sebanyak 2.090 adalah pacar/teman (KemenPPPA, 2018). Kebanyakan data yang dilaporkan memang baru terbatas pada korban kekerasan perempuan dibandingkan laki-laki. Namun perempuan dan laki-laki dapat menjadi korban dari kekerasan ini. Namun memang dari beberapa penelitian yang sudah dilakukan, umumnya korban perempuan dilaporkan mengalami cidera yang lebih parah dibandingkan laki-laki (Schnurr \& Lohman, 2008) dan mengalami level distress yang lebih tinggi (Williams \& Fireze, 2005).

Kekerasan dalam hubungan pacaran merupakan masalah signifikan bagi remaja yang menjadi korbannya. Hal ini disebabkan karena dampak buruk yang dialami dalam kehidupan mereka. Selain dampak dalam hal fisik seperti luka-luka yang terlihat oleh mata, terdapat juga dampak pada kesehatan mental remaja, khususnya psychological well-being mereka (Callahan, Tolman, \& Saunders, 2003).

Dampak yang paling sering ditemukan pada korban kekerasan hubungan pacaran adalah turunnya selfesteem pada diri mereka (Kaura, \& Lohman, 2007; Collin-Vézina, Hébert, Manseau, Blais, \& Fernet, 2006), tingginya gejala depresi dan kecemasan 
(Kaura \& Lohman, 2007), rasa takut (Follingstad, Wright, Llyod, \& Sebastian dalam Callahan dkk., 2003), reaksi benci (Amar \& Gennaro, 2005), gejala somatis seperti perubahan berat badan, sakit kepala, dan gugup atau pusing (Coker, dkk., dalam Kaura \& Lohman, 2007), reaksi stress pascatraumatis dan gejala disosiasi seperti shock, penyangkalan, menarik diri, kebingungan, dan mati rasa secara psikologis (Callahan dkk., 2003). Dari berbagai dampak yang dijelaskan, dampak paling parah yang kemungkinan dapat dialami oleh para remaja korban kekerasan adalah terjadinya stress pascatrauma (PTSD). Hal ini terjadi khususnya jika perlakuan yang diterima sangat kasar (McLeer dkk. dalam Saul, Grant, \& Carter, 2008; Murray, 2007).

Individu dengan stress pascatrauma umumnya memiliki beberapa symptom utama, di antaranya munculnya ingatan berulang yang tidak menyenangkan mengenai kejadian yang menyebabkan trauma (intrusion), menghindari sesuatu yang terkait dengan kejadian traumatis (avoidance), serta meningkatnya arousal yang menyebabkan dirinya kesulitan tidur, sulit berkonsentrasi atau menyelesaikan tugas (hyper-arousal) (American Psychiatric Association, 2013). Kondisi tersebut dapat menghambat seseorang untuk berfungsi dalam kehidupannya sehari-hari. Hal ini disebabkan karena umumnya orang-orang yang mengalami stress pascatrauma akan memiliki ketakutan yang kuat dan merasa tidak berdaya (Murray, 2007).

Beberapa dampak yang dijelaskan di atas menunjukkan bahwa remaja korban kekerasan berpacaran merupakan individu yang berpotensi untuk mengalami gangguan psikologis yang berat. Apabila tidak diatasi dengan lebih cepat, maka kecemasan, ketakutan, rendahnya selfesteem, dan berbagai reaksi pascatrauma yang terjadi pada korban kekerasan akan semakin meluas ke seluruh kehidupan remaja dan mempengaruhi kesejahteraan dirinya. Dalam hal ini, peneliti lebih menekankan pada reaksi stres pascatrauma yang dialami oleh korban kekerasan dalam hubungan pacaran. Apabila reaksi tersebut tidak ditangani dengan cepat, maka individu dapat berpotensi mengalami stress pascatrauma. Oleh karena itu, dibutuhkan adanya suatu intervensi yang bisa membantu remaja korban kekerasan dalam hubungan pacaran untuk mengatasi reaksi yang muncul dan melakukan coping terhadap efek psikologis yang dialaminya dengan lebih cepat.

Pelaksanaan intervensi pada individu yang mengalami reaksi stress pascatrauma dapat dilakukan melalui berbagai cara, baik itu secara individual maupun kelompok. Namun adanya keterbatasan waktu serta semakin banyaknya kasus yang harus ditangani membuat diperlukannya alternatif dalam intervensi dan salah satu alternatif tersebut adalah pelaksanaan intervensi secara kelompok (Stewart, Christner, \& Freeman, 2007). Ditambah lagi dalam penelitian oleh Tilitski (dalam Brabender, Fallon, \& Smolar, 2004) ditemukan bahwa bagi remaja, penanganan secara kelompok merupakan cara yang lebih efektif dibandingkan dengan penanganan individual.

Terdapat beberapa bukti adanya perubahan positif bagi anak-anak dan remaja yang mengikuti terapi kelompok. Di antaranya adalah meningkatnya keterampilan sosial dan berkurangnya masalah sosial, memperbaiki self-esteem, adanya rasa akan kontrol internal yang lebih baik, berkurangnya konsekuensi negatif akibat perceraian orang tua, berkurangnya kecemasan dan depresi di beberapa kelompok, serta menurunnya perilaku bermasalah dan anti sosial (Brabender dkk., 2004). Intervensi yang dilakukan secara kelompok melalui terapi dapat membantu individu yang berada di dalamnya karena terapi kelompok memiliki faktor terapeutik yang berpotensi untuk dirasakan para pesertanya. Diantaranya adalah faktor dukungan, pembukaan diri, pembelajaran melalui 
pengalaman orang lain, serta pembelajaran mengenai hubungan interpersonal. Faktor terapeutik tersebut dapat membantu peserta dalam meringankan kecemasan, membangun self-esteem, dan membantu pesertanya dalam membangun keterampilan dalam hubungan interpersonal (Yalom dalam Mackenzie, 1987; Trull \& Preinstein, 2013; Pomerantz, 2014).

Salah satu penanganan kelompok yang ada dan pernah dilakukan untuk mengatasi reaksi pasca peristiwa traumatis adalah Recovery Technique Manual yang disusun oleh Smith, Dyregrov, \& Yule dari Children and War Foundation di Norwegia pada tahun 1999, bekerja sama dengan UNICEF, UNHCR, dan berbagai LSM. Panduan ini dibuat untuk mengajar para korban langkah demi langkah yang bisa mereka lakukan untuk membangun keterampilan dan beberapa teknik yang bisa membantu mereka mengatasi gejala yang muncul, seperti intrusion, avoidance, dan arousal akibat adanya peristiwa traumatis (Smith, Dyregov, \& Yule, 2008). Banyaknya keberhasilan dengan manual intervensi ini ini membuat peneliti tertarik untuk mencoba mengaplikasikan intervensi yang sama kepada remaja di Indonesia, khususnya remaja korban kekerasan dalam hubungan pacaran.

\section{Formulasi Masalah}

Bagaimana efektivitas intervensi kelompok dengan mengacu pada Recovery Technique Manual dalam mengatasi reaksi stress pascatrauma yang dirasakan oleh remaja korban kekerasan dalam hubungan pacaran?

\section{Tujuan}

Mengetahui efektivitas intervensi kelompok dengan mengacu pada Recovery Technique Manual dalam mengatasi reaksi stress pascatrauma yang dirasakan oleh remaja korban kekerasan dalam hubungan pacaran.
KAJIAN PUSTAKA

Kekerasan dalam Hubungan Pacaran

Kekerasan dalam hubungan

pacaran didefinisikan sebagai

"Penggunaan cara kekerasan yang disengaja dan pemaksaan secara fisik yang bertujuan untuk mendapatkan dan mempertahankan kekuasaan dan kendali terhadap pasangan intim" (The University of Michigan Sexual Assault Prevention and Awareness Center dalam Murray, 2007). Kekerasan ini dilakukan oleh pasangan intim atau mantan pasangan yang umumnya dapat menyebabkan dampak yang membahayakan dalam segi fisik, psikologis, atau seksual (WHO, 2017).

Kekerasan dalam hubungan pacaran terdiri atas beberapa jenis, seperti kekerasan emosional/verbal, kekerasan seksual, kekerasan fisik. Kekerasan emosional biasanya terjadi lebih dulu, jauh sebelum muncul kekerasan fisik (Murray, 2007). Kekerasan ini cenderung menurunkan perasaan keberhargaan diri seseorang. Perilaku yang muncul pada kekerasan jenis cenderung menunjukkan kecemburuan, posesif, dan pengendalian. Kekerasan seksual terlihat dari perilaku seperti rabaan atau sentuhan pada tubuh yang tidak dikehendaki, ciuman yang tidak dikehendaki, pelecehan seksual, adanya pemaksaan fisik untuk melakukan hubungan seksual, atau mengancam dan memanipulasi seseorang dengan menggunakan cara yang memaksa seperti tuduhan yang menyerang status pasangan seksual (Murray, 2007). Kekerasan fisik biasanya merupakan tahapan akhir dalam sebuah hubungan yang menggunakan kekerasan (Murray, 2007). Saat kekerasan fisik muncul, kebanyakan hal ini sudah diawali dengan sejarah panjang adanya kekerasan verbal/emosional dan seringkali terdapat kekerasan secara seksual. Perilaku yang masuk dalam kekerasan fisik biasanya bertujuan untuk menyakiti pasangan seperti memukul, menampar, menendang, mendorong, mencekram dengan keras pada tubuh pasangan dan 
serangkaian tindakan fisik yang lain (KemenPPPA, 2018).

\section{Reaksi Stres Pascatrauma}

Reaksi stres pascatrauma merupakan sebuah respon yang terjadi setelah individu terpapar pada sebuah kejadian traumatis atau sekelompok kejadian yang membuat stress. American Psychiatric Association (2013) mendefinisikan kejadian traumatis sebagai kejadian yang berupa pengalaman atau menyaksikan kejadian yang melibatkan kematian atau ancaman kematian, atau ancaman lain terhadap integritas individu, atau menyaksikan kejadian yang melibatkan kematian, cidera, atau ancaman terhadap integritas fisik orang lain, atau belajar mengenai kematian yang tidak diharapkan, kerugian yang cukup serius, atau ancaman kematian atau cidera yang dialami anggota keluarga atau pihak yang dekat lainnya. Umumnya peristiwa ini terjadi secara tiba-tiba dan dipersepsi sebagai sesuatu yang membahayakan diri atau orang lain (Schiraldi, 2009).

Reaksi stres pascatrauma pada umumnya memiliki gejala yang serupa dengan simtom-simtom utama dari gangguan stress pascatrauma. Simtom pertama adalah adanya pengalaman kembali kejadian traumatis (Reexperience). Individu biasanya memiliki ingatan tidak menyenangkan (intrusive) dan berulang mengenai kejadian tersebut atau mengalami mimpi buruk. Simtom ini juga dapat menyebabkan individu mengalami flashback di mana ia dapat merasakan dan berperilaku seolah-olah kejadian traumatis sedang terjadi (American Psychiatrist Association, 2013). Individu dapat tiba-tiba merasa sangat terganggu oleh hal-hal yang mengingatkan kejadian traumatis tersebut (Friedman, Keane, \& Resick, 2007). Simtom kedua adalah menghindari stimulus atau hal-hal yang berkaitan dengan kejadian traumatis (avoidance). Individu umumnya akan dengan sengaja berusaha menghindari pikiran, perasaan, atau percakapan mengenai kejadian traumatis. Selain itu, seseorang yang mengalami gejala PTSD juga akan menghindari aktivitas, situasi, atau orang-orang yang akan membangkitkan ingatan mengenai kejadian tersebut (American Psychiatrist Association, 2013). Simtom ketiga adalah meningkatnya arousal secara berlebihan (hyper-arousal). Individu umumnya mengalami kesulitan tidur yang kemungkinan disebabkan karena mimpi buruk yang berulang, hypervigilance, cepat marah atau mengalami ledakan kemarahan, atau kesulitan dalam berkonsentrasi atau menyelesaikan suatu tugas (American Psychiatric Association, 2013). Dalam penelitiannya, Saul, dkk (2008) menemukan bahwa simtom reexperiencing, avoidance, emotional numbing, and arousal merupakan simtom yang memang ditemukan pada berbagai remaja yang pernah terekspos dengan kejadian traumatis.

Walaupun teori yang digunakan menggunakan teori mengenai simtom gangguan stress pascatrauma, namun subjek penelitian ini hanya mengalami reaksi stress pascatrauma. Yang membedakan individu dengan gangguan pascatrauma dan individu dengan reaksi stres pascatrauma adalah individu dengan reaksi pascatrauma masih dapat berfungsi dalam kehidupan sosial dan pekerjaan.

\section{Recovery Technique Manual}

Recovery Techique Manual merupakan rancangan intervensi yang disusun oleh Smith, Dyregrov, \& Yule pada tahun 1999 bekerja sama dengan UNICEF, UNHCR, dan berbagai LSM (2008). Manual ini berisi teknik pemulihan kelompok yang sebelumnya telah sering digunakan pada kelompok korban yang selamat dari perang atau bencana alam. Recovery Techique Manual bukan modul treatment untuk menyelesaikan semua simtom dan penyebab munculnya simtom Posttraumatic Stess Disorder (PTSD), melainkan dibuat untuk mencegah 
munculnya simtom yang semakin parah dan tidak terkendali.

Teknik-teknik dalam manual dibuat dengan tujuan membantu anak-anak mengetahui langkah-langkah praktis untuk membangun keterampilan, serta mengatasi efek psikologis dari kejadian yang tidak menyenangkan. Selain itu, keterampilan ini juga dapat membantu mereka untuk mempersiapkan masalah di masa depan yang mungkin akan mereka hadapi.

Manual ini telah berhasil dilakukan dengan kelompok anak-anak yang selamat dari gempa bumi di Turki dan Yunani pada tahun 1999. Selain itu, hal ini juga berhasil dilakukan pada dua kelompok kecil anakanak yang selamat dari gempa bumi di Giannapolou, Atena pada tahun 2000. Hasil yang serupa juga dilaporkan setelah gempa bumi di Bam, Iran pada 2003. Manual ini diberikan pada 42.500 korban selamat dalam 7 bulan pertama setelah gempa bumi. Hasilnya $85 \%$ anak-anak dan remaja yang selamat mengalami penurunan distress.

Manual ini pada awalnya disusun untuk diaplikasikan kepada sekelompok anak korban bencana dan perang sehingga instruksi serta teknik yang diajarkan disesuaikan dengan kondisi dan masalah yang dialami oleh mereka. Pada penelitian ini, manual akan diberikan pada kelompok remaja dengan permasalahan yang berbeda, yaitu korban kekerasan dalam hubungan pacaran dengan kondisi dan permasalahan yang berbeda. Hal ini membuat peneliti melakukan beberapa modifikasi manual yang disesuaikan dengan keadaan partisipan. Beberapa hal yang dimodifikasi antara lain adalah contoh kasus, instruksi, serta pilihan teknik yang akan diajarkan.

Pendekatan yang digunakan dalam pemilihan teknik ini bersifat eklektik, dimana di dalamnya terdapat teknik yang sering dilakukan pada Cognitive Behavior Therapy (CBT), Eye Movement Desensitization and Reprocessing Therapy (EMDR), dan Rational Emotive Behavior Therapy (REBT).

\section{Terapi Kelompok}

Terapi kelompok merupakan pendekatan yang menekankan adanya hubungan interpersonal dalam pelaksanaannya (Pomerantz, 2014). Hubungan ini tidak hanya terbatas antara klien dan terapisnya, namun juga antara klien dan anggota kelompok lainnya. Prinsip dasar terapi kelompok adalah individu dipengaruhi oleh sistem dimana ia berfungsi. Saat ini terapi kelompok diperhitungkan karena memungkinkan adanya treatment dengan biaya yang efektif (Brabender dkk., 2004). Terapi kelompok juga merupakan alternatif intervensi yang bisa dilakukan mengingat adanya keterbatasan waktu serta semakin banyaknya kasus yang harus ditangani oleh para terapis (Stewart dkk., 2007).

Pendekatan terapi kelompok memiliki beberapa faktor terapeutik yang berpotensi untuk dirasakan oleh pesertanya. Pada penelitian awal di tahun 1985, Yalom (dalam McKenzie, 1987; Trull \& Prinstein, 2013) menyatakan terdapat sembilan faktor terapeutik yang dapat ditawarkan oleh intervensi melalui terapi kelompok. Faktor tersebut seperti adanya masukan dari anggota kelompok (imparting information), memunculkan hope, menyadari adanya kesamaan dengan anggota kelompok (universality), altruism, meningkatkan kemampuan interpersonal, dapat mengimitasi perilaku anggota kelompok, memperbaiki kesalahan yang terus berulang dalam keluarga, memfasilitas katarsis, menghasilkan kohesivitas kelompok. Pada tahun 2005, Yalom menambahkan dua faktor yaitu perkembangan teknik dalam bersosialisasi, dan faktor eksistensial sebagai faktor terapeutik terapi kelompok (Pomerantz, 2014).

Tilitski (dalam Brabender, dkk, 2004) menemukan bahwa bagi remaja, penanganan secara kelompok merupakan cara yang lebih efektif dibandingkan dengan penanganan individual. Hal ini juga didukung oleh pernyataan Trull dan Prinstein (2013) di mana terapi kelompok 
merupakan pendekatan yang cukup populer saat menghadapi anak dan remaja. Hal ini disebabkan karena mereka lebih nyaman dengan setting sejenis kelas, pendekatan ini cukup tepat untuk mengurangi perilaku agresif, kecemasan, atau kemampuan interpersonal yang sering dialami oleh anak maupun remaja.

\section{METODOLOGI PENELITIAN Partisipan}

Pada penelitian ini peneliti menetapkan beberapa kriteria untuk mendapatkan subjek penelitian, yaitu: 1) Laki-laki dan perempuan yang berada pada tahapan perkembangan remaja dengan rentang usia 12-22 tahun; 2) Pernah mengalami kekerasan dalam hubungan pacaran, baik kekerasan fisik, emosional, maupun seksual dan saat ini sudah tidak berada dalam hubungan dengan pasangan yang melakukan kekerasan; 3) Memiliki total skor CRIES-13 diatas angka 17 (pada aspek intrusion dan avoidance) atau skor yang cukup tinggi pada aspek arousal ; 4) Bersedia mengikuti intervensi kelompok yang dilakukan oleh peneliti sebanyak lima kali pertemuan dengan mengisi informed consent

\section{The Children Impact of Events Scale - 13 (CRIES-13)}

Penelitian ini menggunakan kuesioner CRIES-13 (The Children Impact of Events Scale-13) yang digunakan oleh Smith, Dyregrov, dan Yule (2008) dalam intervensinya untuk untuk mengetahui tingkat reaksi stres pasca kejadian traumatis pada seseorang yang mengalaminya. Hasil ujicoba kuesioner adaptasi CRIES-13 menunjukkan hasil yang valid dan reliabel dengan nilai Cronbach Alfa 0,734 serta inter-item correlation dalam range 0.025 0.631 . Untuk item-item dengan nilai interitem correlation di bawah 0.2 , dilakukan analisa secara kualitatif dan akhirnya diubah pernyataannya.

\section{Desain Penelitian}

Penelitian ini menggunakan desain one-group pretest-post-test design. Desain penelitian ini menggunakan satu kelompok subjek dalam jumlah kecil yang diberi intervensi tanpa kelompok pembanding, atau dapat disebut sebagai penelitian kuasi eksperimental (Kerlinger \& Lee, 2000).

\section{Prosedur}

Peneliti menggunakan purposive sampling untuk menentukan subjek penelitian. Peneliti menyebarkan informasi mengenai penelitian dengan menggunakan media cetak (flyer), media elektronik (melalui situs jaringan sosial), serta bertanya kepada orang-orang terdekat untuk mencari informasi mengenai kasus kekerasan dalam hubungan pacaran di sekitar mereka. Setelah mendapatkan calon partisipan, peneliti melakukan wawancara singkat mengenai sejarah kekerasan yang dialami dan efek yang dirasakan saat ini. Peneliti juga meminta mereka mengisi CRIES-13 dan akan memilih orang-orang yang memiliki skor CRIES-13 di atas 17 pada aspek intrusion dan avoidance.

Tabel 1. Rancangan Intervensi

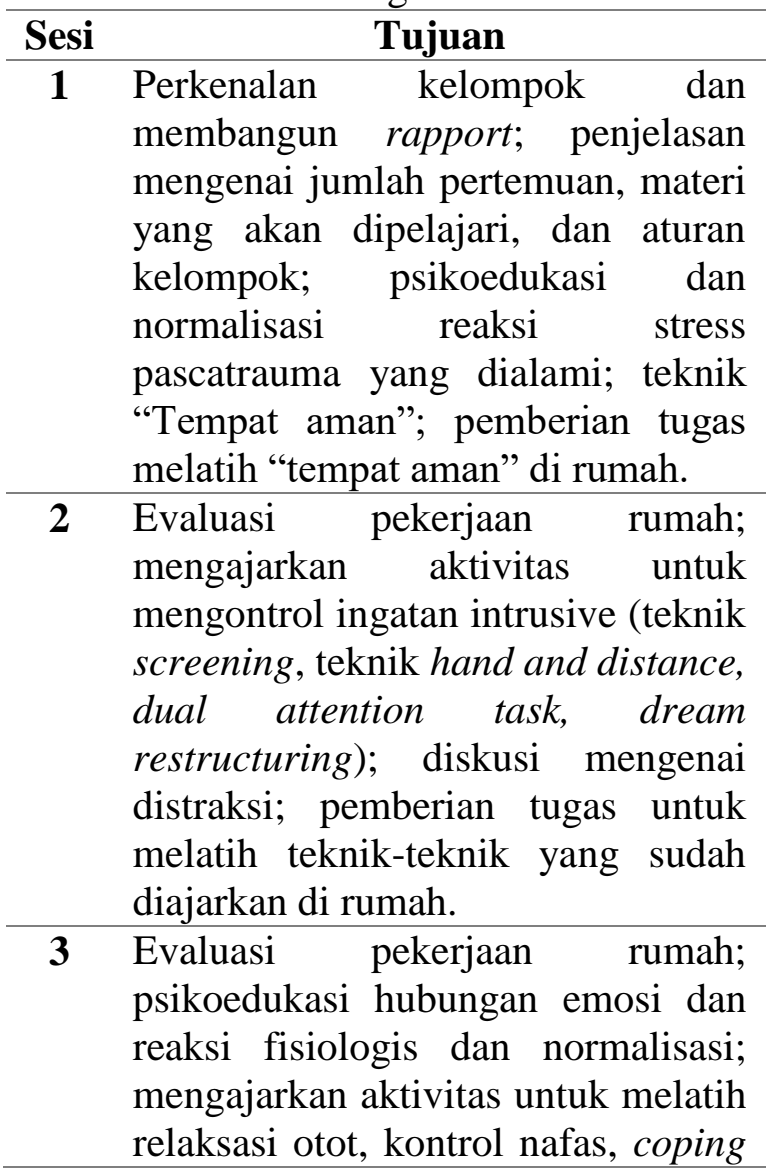




\begin{tabular}{ll}
\hline Sesi & \multicolumn{2}{c}{ Tujuan } \\
& self-statement; pemberian tugas \\
& melatih teknik relaksasi di rumah. \\
\hline 4 & Evaluasi pekerjaan rumah; \\
& psikoedukasi mengenai pengingat - \\
& rasa takut - keterpaparan - perilaku \\
& menghindar; memperkenalkan dan \\
& membuat tangga ketakutan masing- \\
& masing partisipan; latihan mengatasi \\
& keterpaparan secara imajinatif (in \\
& vivo); mempersiapkan diri \\
& menghadapi keterpaparan di \\
& kehidupan nyata; pemberian tugas \\
& melatih teknik keterpaparan di \\
& rumah. \\
\hline Evaluasi pekerjaan rumah; aktivitas \\
kelompok (teknik menghadapi \\
keterpaparan melalui kegiatan \\
menggambar, menulis, bercerita); \\
diskusi mengenai masa depan yang \\
ingin diraih, penutup.
\end{tabular}

\section{Teknik Analisis}

Penelitian ini dianalisis secara deskriptif melalui perubahan skor (skor sebelum dan sesudah sesi terapi diberikan). Intervensi ini dinilai efektif jika terdapat penurunan skor di akhir intervensi. CRIES-13 digunakan untuk mengetahui skor pre-test dan post-test dari gejala stress pascatrauma. Teknik wawancara dan observasi terhadap subjek pada seluruh rangkaian intervensi juga digunakan untuk turut memberikan indikasi efektivitas intervensi. Secara keseluruhan perbedaan skor pre-test dan post-test, serta evaluasi seluruh observasi dan wawancara akan menjadi tolak ukur efektivitas intervensi.

\section{HASIL PENELITIAN DAN ANALISIS}

Dari proses penyebaran informasi mengenai penelitian ini, peneliti mendapatkan 6 remaja perempuan yang mengaku pernah mengalami kekerasan dalam hubungan pacaran. Setelah melakukan screening melalui pengisian kuesioner CRIES-13 dan wawancara, didapatkan 2 partisipan yang memenuhi kriteria dan bersedia mengikuti penelitian.
Di bawah ini, Tabel 2 menjelaskan hasil screening pada dua subjek terpilih:

Tabel 2. Hasil Screening

\begin{tabular}{ccc}
\hline $\begin{array}{c}\text { Aspek } \\
\text { Pengukuran }\end{array}$ & Subjek 1 & Subjek 2 \\
\hline CRIES - 13 & $\begin{array}{c}\text { Intrusion 13, } \\
\text { Avoidance 20, } \\
\text { Arousal 14 }\end{array}$ & $\begin{array}{c}\text { Intrusion 12, } \\
\text { Avoidance 18, } \\
\text { Arousal 15 }\end{array}$ \\
\hline Jenis Kekerasan & $\begin{array}{c}\text { Emosional/ } \\
\text { verbal }\end{array}$ & $\begin{array}{c}\text { Emosional/ } \\
\text { verbal }\end{array}$ \\
\hline
\end{tabular}

\section{Identitas Subjek}

Tabel 3. Data Diri Subjek Penelitian

\begin{tabular}{|c|c|c|}
\hline Data Diri & Subjek 1 & Subjek 2 \\
\hline Jenis Kelamin & Perempuan & Perempuan \\
\hline Usia & 18 tahun & 21 tahun \\
\hline Domisili & Depok & Depok \\
\hline Suku & $\begin{array}{l}\text { Melayu } \\
\text { (Jambi) }\end{array}$ & Betawi \\
\hline $\begin{array}{l}\text { Pekerjaan saat } \\
\text { ini }\end{array}$ & $\begin{array}{l}\text { Mahasiswi } \\
\text { (S1) }\end{array}$ & $\begin{array}{l}\text { Mahasiswi } \\
\text { (S1) }\end{array}$ \\
\hline Agama & Islam & Islam \\
\hline
\end{tabular}

\section{Gambaran Kekerasan yang Dialami dan Reaksi Stres Pascatrauma Subjek}

Peneliti melakukan wawancara mengenai sejarah pacaran, perilaku kekerasan yang dialami mantan pacar, dan juga gambaran reaksi stres pascatrauma yang dialami oleh kedua subjek. Di bawah ini merupakan hasil kesimpulan dari wawancara tersebut:

\section{Subjek 1}

Kekerasan dalam hubungan pacaran yang dialami subjek 1 adalah emosional/verbal. Pasangan subjek melakukan pembatasan interaksi antara subjek dengan teman-teman lelakinya, selalu memeriksa handphone subjek, dan menyudutkan subjek dengan mengatakan bahwa perempuan berada di bawah lakilaki.

Subjek mengaku bahwa pikiranpikiran tidak menyenangkan mengenai perilaku mantan pacar sering muncul, terutama saat ia sendirian di kamar. Saat pikiran tersebut muncul, rasa kesal selalu ia rasakan. Saat melihat laki-laki yang mirip dengan mantan pacarnya, ia juga cenderung menghindarinya. Ia juga menghindari barang-barang atau warna 
tertentu yang mengingatkannya pada mantan pacarnya.

\section{Subjek 2}

Kekerasan dalam hubungan pacaran yang dialami subjek 2 adalah emosional/ verbal dan juga seksual. Pasangan subjek melarang subjek melakukan aktivitas yang biasanya ia lakukan, menyudutkan subjek saat mereka sedang berkonflik, serta sering meminta subjek berhubungan seksual

Subjek mengaku menghindari kampus, jalan menuju kos mantan pacar, atau jalan di mana mantan pacar pernah marah dan membanting handphone. Ia merasa takut saat mengingat hal tersebut. Subjek juga sering teringat perilaku mantan pacar yang sering marah dan menyakiti dirinya. Hal itu membuatnya sering menangis tiba-tiba. Ia juga menjadi cemas saat menerima pesan singkat di handphone-nya karena mengingatkannya akan perilaku mantan pacar yang sering marah atau sering meminta dirinya berhubungan seksual melalui pesan singkat.

\section{Efektivitas Intervensi}

Hasil pre-test-post-test dalam penelitian ini dijelaskan melalui tabel berikut.

Tabel 4. Hasil perbandingan CRIES-13 pada subjek

\begin{tabular}{lcc} 
& \multicolumn{2}{c}{ pada subjek } \\
\hline Pre-Test & Post-test \\
\hline Subjek 1 & Intrusion 13 & Intrusion 2 \\
& Avoidance 20 & Avoidance 1 \\
& Arousal 14 & Arousal 1 \\
\hline Subjek 2 & Intrusion 12 & Intrusion 6 \\
& Avoidance 18 & Avoidance 8 \\
& Arousal 15 & Arousal 5 \\
\hline
\end{tabular}

Terlihat bahwa intervensi

kelompok yang dilakukan dalam lima sesi pertemuan cukup berpengaruh terhadap penurunan reaksi stres pascatrauma kedua subjek. Analisis data perubahan skor (pretest dan post-test) tersebut menunjukkan bahwa terdapat penurunan pada masingmasing dimensi CRIES-13. Subjek 1 mengalami penurunan dalam intrusion sebanyak 11 skor, avoidance sebanyak 19 skor, dan arousal sebanyak 13 skor. Sedangkan pada subjek 2 terjadi penurunan intrusion sebanyak 6 skor, avoidance sebanyak 10 skor, dan arousal sebanyak 10 skor.

Selain dilihat dari pengukuran secara kuantitatif, hasil intervensi ini juga dianalisis secara kualitatif melalui observasi dan wawancara. Dari hasil wawancara diketahui bahwa teknik-teknik yang diajarkan dapat dilakukan serta dipraktekkan di luar pertemuan oleh kedua subjek dengan baik. Dari beberapa teknik tersebut, para subjek lebih sering melatih teknik tempat aman, coping self-statement (mantra), serta pengaturan pernapasan. Hal ini dilakukan karena tidak membutuhkan waktu yang lama dan efeknya dapat dirasakan lebih cepat. Pelaksanaan teknik tersebut diakui oleh partisipan dapat membantu mereka untuk menjadi lebih tenang, dapat mengatur emosi negatif yang sering dirasakan ketika mengingat kejadian traumatis, serta menurunkan kecemasan. Teknik ini juga tidak hanya dilakukan untuk membantu mengatasi emosi akibat ingatan akan kejadian traumatis, yaitu kekerasan dalam hubungan pacaran, yang mereka alami, tetapi juga emosi yang disebabkan karena situasi lain yang mereka hadapi. Selain itu, teknik seperti relaksasi otot dapat digunakan untuk membantu subjek yang mengalami kesulitan tidur.

Selama menjalani latihan teknik, teknik dual attention task (tapping) membuat partisipan bereaksi karena menimbulkan emosi negatif yaitu kesal. Hal yang sama juga terjadi pada saat latihan keterpaparan imajinasi dimana saat itu Subjek 1 merasa kesal dan Subjek 2 merasa cemas. Mereka berdua pada awalnya sama-sama ingin memberhentikan latihan yang dilakukan karena munculnya perasaan tersebut. Namun perasaan itu pada akhirnya bisa diatasi dengan melakukan teknik coping self-statement (mantra) dan pengaturan pernapasan. 
Selama mengikuti pertemuan dan melakukan teknik yang diajarkan, kedua partisipan mengakui adanya perubahan positif di dalam diri yang mereka rasakan. Keberhasilan dalam melakukan teknik yang diajarkan membuat mereka menjadi percaya diri dalam mengatasi masalah yang dihadapinya. Selain itu, teman-teman di sekitar mereka juga menyatakan bahwa saat ini para partisipan terlihat menjadi lebih riang dan tenang. Akibat perubahan yang dirasakan, partisipan mencoba mengajarkan teknik yang mereka ketahui kepada teman-teman yang membutuhkan bantuan.

Proses intervensi secara berkelompok menurut subjek membantu mereka mengetahui bahwa mereka tidak sendiri. Walaupun dalam kelompok hanya terdiri atas dua partisipan, namun proses keterbukaan di dalam kelompok dapat terlaksana dengan baik. Sejak pertemuan pertama, kedua partisipan sudah menceritakan pengalaman kekerasan yang dialaminya. Mereka juga saling mendukung satu sama lain dengan menimpali pendapat dan melakukan afirmasi perasaan. Namun kedua partisipan juga menyatakan bahwa akan lebih baik jika partisipan yang ikut lebih banyak sehingga mereka mendapatkan lebih banyak teman berbagi.

\section{Analisis}

Selama proses pelaksanaan intervensi, kedua subjek terus melatih teknik-teknik yang telah diajarkan di rumah. Hal ini membuat berkurangnya simtom yang mereka rasakan di akhir intervensi. Hal ini sesuai dengan pernyataan para pembuat modul intervensi ini. Smith, Dyregov, \& Yule (2008) menyatakan bahwa keefektivitasan sebuah teknik tergantung kepada latihan yang dilakukan oleh individu yang menjadi pesertanya. Mereka juga menyatakan bahwa individu yang telah mempelajari dan juga mempraktekkan teknik yang diberikan juga tidak akan memerlukan treatment lanjutan di masa yang akan datang.

Dari ketiga gejala stress pascatrauma, yang mengalami penurunan yang cukup besar terjadi pada gejala avoidance dan arousal dibandingkan intrusion. Hasil analisis kualitatif melalui wawancara menjelaskan bahwa teknikteknik yang paling sering dilakukan subjek penelitian adalah teknik yang tidak membutuhkan waktu lama dan efeknya segera dirasakan seperti teknik tempat aman, coping self-statement (mantra), serta pengaturan pernapasan. Teknik-teknik tersebut diketahui merupakan teknik yang ditujukan untuk gejala arousal dan avoidance.

Selama mengikuti pertemuan dan melakukan teknik yang diajarkan, partisipan mengalami perubahan di dalam diri yang mereka rasakan. Kemampuan partisipan untuk melakukan teknik yang diajarkan serta adanya pengalaman keberhasilan dalam melaksanakan teknik tersebut membuat partisipan merasa dirinya memiliki rasa percaya diri karena mampu mengatasi masalah yang selama ini tidak dapat ia atasi. Rasa mampu mengatasi masalah ini menunjukkan adanya self-efficacy yang baik pada partisipan. Self-efficacy ini disadari memiliki pengaruh yang cukup kuat dalam mengatasi respon yang menekan (Cohen, dkk; Sarafino; Thompson dalam Lating \& Everly, 2003).

Self-efficacy merupakan salah satu hal yang dapat mempengaruhi self-esteem. Hal ini disebabkan karena individu memiliki penilaian positif terhadap diri sendiri, yaitu memiliki kompetensi dalam penyelesaian masalah (Lating \& Everly, 2003). Evaluasi ini merupakan hal positif yang bisa didapatkan partisipan karena pada umumnya para korban kekerasan dalam hubungan pacaran memiliki selfesteem yang rendah dan memandang negatif diri mereka (Kaura \& Lohman, 2007).

$$
\text { Intervensi yang diberikan }
$$
dilakukan dalam bentuk kelompok. 
Kemampuan anggota kelompok untuk melihat kesamaan di antara dirinya dan anggota yang lain merupakan prinsip universalitas yang menjadi faktor terapeutik tersendiri bagi anggotanya dan mendukung kohesivitas kelompok melalui kehangatan dan penerimaan anggota kelompok yang lain (Yallom dalam Trull \& Prinstein, 2013; Pomerantz, 2014). Hal ini membuat para subjek akhirnya menyadari bahwa terdapat orang lain dengan masalah yang sama sehingga mereka tidak sendiri. Keberadaan orang lain di dalam kelompok sudah menunjukkan adanya proses terapeutik tersendiri bagi para subjek.

\section{KESIMPULAN}

Berdasarkan pelaksanaan penelitian dan diskusi dapat disimpulkan bahwa penerapan intervensi kelompok yang menggunakan Recovery Technique Manual efektif untuk menurunkan gejala stres pascatrauma pada kedua subjek penelitian.

Peneliti ke depannya diharapkan untuk melakukan penelitian lanjutan menggunakan Recovery Technique Manual dalam kelompok dengan jumlah subjek yang lebih banyak. Selain itu perlu juga dilakukan intervensi menggunakan modul ini pada individu yang pernah mengalami jenis kekerasan yang berbeda (fisik dan seksual). Peneliti selanjutnya juga diharapkan dapat melakukan followup setelah intervensi untuk mengetahui dampak jangka panjang yang dirasakan.

Secara praktis, peneliti yang akan menggunakan modul intervensi kelompok ini diharapkan untuk selalu mendorong individu yang mengikuti intervensi untuk melatih teknik-teknik yang diajarkan. Selain itu, teknik-teknik yang diajarkan pada intervensi ini cukup praktis dan dapat dilakukan banyak orang. Pemberian intervensi dalam bentuk workshop dengan kelompok-kelompok kecil dapat dilakukan agar dapat membantu lebih banyak individu.
Sedangkan bagi subjek penelitian ataupun individu lain yang mengalami stress pascatrauma dan pernah mempelajari teknik-teknik yang terdapat dalam modul ini diharapkan dapat terus melatih teknik yang diberikan. Selain itu, untuk meningkatkan kepercayaan diri yang dimiliki, maka subjek perlu membuat catatan keberhasilan yang selama ini sudah berhasil dicapai agar dapat dibaca kembali. Subjek maupun individu yang pernah menjadi korban kekerasan dalam pacaran dan mengalami reaksi stress pascatrauma dapat mempertahankan relasi dengan orang-orang terdekat atau masuk dalam komunitas yang aktif dalam pencegahan kekerasan dalam hubungan pacaran agar memperoleh dukungan bagi dirinya.

\section{DAFTAR PUSTAKA}

1. Amar, A.F., \& Gennaro, S., Dating violence in college women: Associated physical injury, healthcare usage, and mental health symptoms, Nursing Research, 54, 235 - 242, 2005.

2. American Psychiatric Association, Diagnostic and statistical manual of mental disorder (DSM-5) ( $5^{\text {th }} \mathrm{Ed}$.). Arlington: British Library Cataloguing in Publication Data, 2013.

3. Brabender, A., Fallon, A.E., \& Smolar, A.I., Essentials of group therapy. New Jersey: John Wiley \& Sons, Inc, 2004.

4. Callahan, M.R., Tolman, R.M., \& Saunders, D.G., Adolescent dating violence victimization and psychological well-being. Journal of Adolescent Research, 18, 664 - 681, 2003.

5. Centers for Disease Control and Prevention (CDC), Teen dating violence, diunduh dari https://www.cdc.gov/violencepreventi on/intimatepartnerviolence/teen_datin g_violence.html, 2018.

6. Collin-Vézina, C., Hébert, M., Manseau, H., Blais, M., Fernet, M., Self-concept and dating violence in 220 adolescent girls in the child 
protective system, Child Youth Care Forum, 35, 319 - 326, 2006.

7. Friedman, M.J., Keane, T.M., \& Resick, P.A. (Eds), Handbook of PTSD: Science and practice. New York: Guilford Press, 2007.

8. Kaura, S.A., \& Lohman, B.J., Dating violence victimization, relationship satisfaction, mental health problems, and acceptibility of violence: A comparison of men and women, Journal Family Violence, 22, 367-381, 2007.

9. Kementrian Pemberdayaan Perempuan dan Perlindungan Anak (KemenPPPA), Waspada Bahaya Kekerasan Dalam Pacaran, diunduh dari

https://www.kemenpppa.go.id/index.p $\mathrm{hp} /$ page/read/31/1669/waspadabahaya-kekerasan-dalam-pacaran, 2018.

10. Kerlinger, F. N., \& Lee, H. B., Foundation of behavioral research $\left(4^{\text {th }}\right.$ Ed. $)$, Orlando, FL: Harcourt, 2000.

11. Komisi Nasional Perempuan, Catatan kekerasan terhadap perempuan tahun 2017, diunduh dari https://www.komnasperempuan.go.id/ file/pdf_file/2018/Publikasi/Catatan\% 20Tahunan\%20Kekerasan\%20Terhad ap\%20Perempuan\%202018.pdf, 2018.

12. Lating, J.M., \& Everly Jr., G.S., Personality-guided therapy for posttraumatic stress disorder. Washington: American Psychological Association, 2003.

13. MacKenzie, K.R., Therapeutic factors in group psychotherapy, Group 11(1), 26-34, 1987.

14. Murray, J., But i love him: Protecting your teen daughter from controlling, abusive dating relationships. Canada: HarperCollin, 2007.

15. Pomerantz, A.M., Clinical psychology: Science, practice, and culture. California: SAGE Publications, Inc, 2014.
16. Rice, F.P., The Adolescent: Development, relationship, and culture ( $\left.9^{\text {th }} \mathrm{Ed}.\right)$, Massachusetts: Allyn \& Bacon, 1999.

17. Saul, A.L., Grant, K.E., \& Carter, J.S., Post-traumatic reactions in adolescents: How well do the DSM-IV PTSD criteria fit the real life experience of trauma exposed youth?, Journal of Abnormal Child Psychology, 36, 915-925, 2008.

18. Shiraldi, G.R., The post-traumatic stress disorder sourcebook, USA: The McGraw-Hill, 2009.

19. Schnurr, M.P., \& Lohman, B.J., How much does school matter? An examination of adolescent dating violence perpetration, Journal of Youth and Adolescence, 37, 266-283, 2008.

20. Smith, P., Dyregov, A., \& Yule, W., Children and disaster: Teaching recovery techniques (Rev.Ed). Bergen: Children and War Foundation, 2008.

21. Stewart, J.L., Christner, R.W., \& Freeman, A. (Eds), Handbook of cognitive-behavior group therapy with children and adolescents. Routledge: New York, 2007.

22. Trull, T.J., \& Prinstein, M.J., The science and practice of clinical psychology $\quad\left(8^{\text {th }} \quad\right.$ Ed.). Canada: WADSWORTH CENGAGE Learning, 2013.

23. Williams, S.L., \& Frieze, I.H., Patterns Of Violent Relationship, Psychological Distress, And Marital Satisfaction In A National Sample Of Men And Women. Sex Roles, 52, 771 - 784, 2005.

24. World Health Organization (WHO), Violence Against Women, diunduh dari http://www.who.int/en/newsroom/fact-sheets/detail/violenceagainst-women, 2017. 